\title{
PIBID CAPES-MEC e PIBID UFF-COLUNI - Políticas públicas, história, trajetórias e marcas
}

\author{
PIBID CAPES-MEC and PIBID UFF-COLUNI - Public policies, history, \\ trajectories and brands \\ PIBID CAPES-MEC y PIBID UFF-COLUNI - Políticas públicas, historia, \\ trayectorias y marcas
}

\section{ROBERTA LOPES ALFRADIQUE HARDOIM IDUINA MONT'ALVERNE BRAUN CHAVES}

\begin{abstract}
Resumo: Este artigo apresenta o sentido da experiência do PIBID com a UFF e as suas contribuições para os professores, para a escola e para as licenciaturas. $\mathrm{O}$ estudo se fundamenta na Complexidade de Morin, nos estudos sociológicos de Maffesoli, nos antropológicos de Durand e na Pesquisa Narrativa de Chaves. As conclusões apontam para o potencial formativo do PIBID que não se restringe ao âmbito da formação inicial, alcançando também, a formação continuada, e para a contribuição de um processo de (auto/trans)formação que revitalizou e regenerou os modos de pensar, sentir e agir dos sujeitos envolvidos.
\end{abstract}

Palavras-chave: PIBID UFF; Complexidade; Pesquisa Narrativa; Formação

\begin{abstract}
This paper presents the meaning of PIBID's experience with UFF and its contributions to teachers, schools and undergraduate students. The study is based on Morin Complexity, on Maffesoli Sociological Studies, on Durand Anthropological Studies, and on Chaves Narrative Research. The conclusion shows the formative potential of PIBID, which is not restricted to the scope of initial formation, but also to continuing education, and to the contribution of a process of (self/trans)formation that revitalized and regenerated the ways of thinking, feeling, and acting of the subjects involved.
\end{abstract}

Keywords: PIBID UFF; Complexity; Narrative Research; Formation

Resumen: Este artículo presenta el significado de la experiencia de PIBID con la UFF y sus contribuciones a los profesores, a la escuela y a los profesorados. El estudio se basa en la Complejidad de Morin, en los estudios sociológicos de Maffesoli, en los estudios antropológicos Durand y la Investigación Narrativa de Chaves. Las conclusiones apuntan al potencial formativo de PIBID, que no se limita al alcance de la formación inicial, sino también a la educación continua, y a la contribución de un proceso de formación (auto/trans) que revitalizó y regeneró las formas de pensar, sentir y actuar de los sujetos involucrados.

Palabras clave: PIBID UFF; Complejidad; Investigación Narrativa; Formación 


\section{INTRODUÇÃO \\ CAMINHOS E PILARES QUE DÃO SUSTENTAÇÃO AO ESTUDO}

O objetivo desta pesquisa foi compreender o sentido da experiência do PIBID, no âmbito da UFF, para a formação continuada dos professores da Educação Básica, dos professores do Ensino Superior, bem como, as suas contribuições para a escola e para os cursos de licenciatura dessa universidade, segundo esses sujeitos.

No que diz respeito ao campo da pesquisa, tal estudo, como já foi dito, foi realizado no âmbito da UFF, tendo como foco a participação desta instituição no PIBID a partir da implementação de um dos seus subprojetos, vinculado ao curso de Pedagogia, no $1^{\circ}$ segmento do Ensino Fundamental do Colégio Universitário Geraldo Aquiles Reis (COLUNI/UFF). Quanto aos sujeitos, no contexto do COLUNI/UFF, contamos com a participação de 03 (três) professoras que atuam como supervisoras do PIBID, e da Coordenadora Pedagógica do Ensino Fundamental I; já no cenário da Universidade, colaboraram a Coordenadora Institucional do PIBID e a última coordenadora de área do PIBID no COLUNI. Com relação à metodologia, adotamos pressupostos que estivessem em sintonia com os preceitos teóricos que fundamentaram esta pesquisa.

Morin (2010) aponta para a necessidade de uma "reparadigmatização" da ciência que torne possível uma mudança de visão da realidade e, consequentemente, da ação social. Isso porque, segundo ele, há um esgotamento do paradigma dominante de ciência, nutrido por uma razão técnica, que privilegia, dentre outras coisas: o racionalismo, a objetividade científica, a ontologia dicotômica, a epistemologia objetiva/analítica, a metodologia empírica, a causalidade determinista e a lógica disjuntiva, simplificadora, reducionista e excludente. Para ele, este processo se constitui, basicamente, da passagem dos fundamentos de uma razão fechada até a configuração de uma razão complexa (aberta). No entanto, vale ressaltar que Chaves (1999), ao se basear nos pressupostos de Morin, assinala que essa transição de uma razão para outra não se dá de forma linear.

Diante disso e da "revolução paradigmática", Morin (Ibid) nos propõe pensar o novo paradigma a partir do pensamento complexo, o qual busca romper com a ideia de um saber fragmentado que não dá conta de compreender o conhecimento, nem mesmo o conhecimento do conhecimento. Todavia, devido ao fato de a complexidade só ter sido tratada marginalmente, tanto no pensamento científico como no pensamento epistemológico e no filosófico, Morin nos alerta para os muitos equívocos que o uso deste termo pode suscitar. Ao se falar de complexidade, Morin não pretende apontá-la como alternativa à perspectiva simplificadora do paradigma tradicional de ciência, ou como metodologia, ou 
como uma nova metafísica, ou, ainda, como "resposta". Ao contrário, o que se busca é compreendê-la como um desafio e uma possibilidade que nos incitam a desenvolver novas formas de pensar e de agir, as quais permitam a compreensão do real de uma maneira mais ampliada, reconhecendo nele aquilo que as definições simplificadoras não conseguem perceber: sua multidimensionalidade.

Assim, assumir o Paradigma da Complexidade como pressuposto teórico significou reconhecer que a simplificação por si só obscurece as inter-relações existentes entre todos os fenômenos da realidade. Olhar o ser o humano a partir desse paradigma, permitiu concebê-lo como um todo, ou seja, como um ser simultaneamente físico, biológico, social, cultural e psíquico. Aliás, o próprio Morin afirma que "o desafio da epistemologia complexa é fazer comunicar as instâncias separadas do conhecimento" (1983).

Aqui entra em cena o que Morin chama de princípio dialógico, característica fundamental do pensamento complexo, já que possibilita unir conceitos que tradicionalmente se opõem, os quais, por terem sido considerados racionalmente antagônicos, se encontravam em compartimentos fechados, sem estabelecer nenhuma relação. Esse mesmo princípio nos leva a compreender que o ser humano é, ao mesmo tempo, biopsicossociocultural dentro de uma dinâmica antagônica, concorrente e complementar. (MORIN, 2010, p. 334).

Dessa forma, ao se partir da noção ${ }^{1}$ de "reparadigmatização", a qual toma como fundamento a necessidade de se estabelecer uma mudança de visão de mundo, é possível conceber o homem, a sociedade, os modos de pensar o conhecimento e de entender a realidade segundo a perspectiva de uma razão aberta que se baseia numa lógica não-binária que aceita o antagonismo, a contraditorialidade e a complexidade.

Assim, quando nos predispusemos a olhar complexamente a implementação do PIBID na formação de professores no âmbito da UFF e do COLUNI foi possível compreender não só a "dimensão prosaica" ("atividades racionais/empíricas"), mas, principalmente, a "dimensão poética” que (“[...] joga com a analogia e a metáfora, tenta traduzir as emoções e os sentimentos, permite à alma exprimir-se") $)^{2}$ (MORIN, 2011a, 169), o que é facilitado por uma "visão estereoscópica", a qual se contrapõe a uma visão monocular do mundo e permite o entendimento das diferentes dimensões da realidade. Com isso, foi possível apresentar como o PIBID CAPES-MEC e o PIBID UFF-COLUNI

\footnotetext{
1 Michel Maffesoli (2010) propõe a ideia de noção em detrimento da de conceito. Para ele, o conceito tem o "dever ser" como lógica e apresenta certa rigidez e unidade. Já a noção, torna possível a compreensão da labilidade, da heterogeneidade e do inacabamento do social.

2 Ao longo do texto, as noções dimensão prosaica e dimensão poética serão utilizadas segundo esse entendimento.
} 
se configuraram e se organizaram através da análise dos documentos legais que trataram desse programa nessas instituições e também compreender os "modos de pensar, sentir e agir" das professoras e, para este trabalho, da bolsista pibidiana, Sofia, que atuou na Educação Básica (COLUNI) naquela época. Modos de pensar, sentir e agir que Morin (2011b) entende como cultura: “[...] capital cognitivo, técnico e mitológico não inato" (p. 208).

Já Maffesoli, fundamentado na Fenomenologia Compreensiva, da qual produziu sua Sociologia do Cotidiano, aponta para a importância de se focar nas múltiplas e pequenas situações e práticas da vida cotidiana sem desconsiderar a importância do econômico ou da razão. Isso porque, "ao lado de uma representação homogênea e globalizante do dado social, existe uma socialidade multiforme, subterrânea e tenaz que é vivida [...]" (MAFFESOLI, 1979). Essa socialidade comporta "um processo rico em acasos, feito de moleza e passividade, que avança ao ritmo das paixões, encontros, coerções e das pequenas mortes de todos os dias" (Ib, p. 63). Dessa forma, fazer uso das ideias-força que regem o pensamento maffesoliano permitiu perceber o cotidiano não como um simples espaço em que se pesquisou, mas como uma possibilidade de entendimento do real e, até mesmo, como uma "alavanca metodológica" (MAFFESOLI, 1995).

Dessa forma, ao olhar as contribuições do PIBID para a formação da professora supervisora Sofia (que representa as outras participantes do estudo) no âmbito do COLUNI/UFF, o que se pretendeu foi compreender não só o "lado iluminado" (as normas, a legislação etc.), mas também o "lado sombra", ou melhor, as "mínimas situações do dia a dia, que constituem parte essencial da trama social, um conhecimento empírico cotidiano - estes "saber-fazer e saber-viver" -, cuja riqueza não pode ser dispensada” (CHAVES, 2000, p. 63). Sendo assim, o cotidiano foi visto como um lugar privilegiado da análise social por admitir que os enfoques microestruturais, dentro de um quadro epistemológico ampliado, possam permitir o entendimento daquilo que ocorre efetivamente no cotidiano de uma dada instituição e, nesse caso específico, possibilitou compreender o universo simbólico dessa professora pibidiana.

Seguindo essa lógica, foi possível mostrar os caminhos que o PIBID veio trilhando até 2018 no rumo de se construir uma formação que se apresente como uma alternativa aos modos tradicionais de se pensar e fazer a formação continuada de professores. E, nesse sentido, apresentar os pontos positivos, as inovações, os avanços e, também, os limites, as dificuldades, as invariâncias, os fracassos, enfim, percorrer o trajeto que vai daquilo que é instituído, do "dever ser" - sua estrutura individual/racional - até o cenário representacional, o instituinte, o viver social dessa formação - sua estrutura societal/afetiva. 
Em harmonia com os pressupostos teóricos morianianos e maffesolianos apresentados até aqui, a obra de Durand também se assenta numa nova configuração paradigmática. Ao constituir uma Antropologia do Imaginário, mais exatamente uma hermenêutica antropológica, procurou compreender o homem como produtor de imagens e o estudo do imaginário como responsável por "apreender, nos componentes fundamentais do psiquismo humano, as estruturas profundas arquetípicas, nas quais se ancoram as representações simbólicas e o pensamento" (CHAVES, 2011, p. 10). Nesse sentido, Durand desenvolveu sua Teoria Geral do Imaginário, tomando como premissas a integração entre imaginário e razão e as críticas à desvalorização ontológica da imagem e à depreciação psicológica da função da imaginação no pensamento ocidental clássico.

E nesse contexto, a noção de imagem se ancora na ideia de símbolo e não na de signo. Araújo; Baptista (2003) nos explicam muito bem essa diferença:

Assim sendo, enquanto o conceito ou o signo convencional é um instrumento de comunicação elaborado conscientemente e conscientemente comprovado e controlado que tem um caráter referencial, o símbolo seria mais uma expressão espontânea da personalidade na sua totalidade. $O$ que significa que nele se expressa tanto a personalidade consciente como a inconsciente, [...] (p. 79).

Sendo assim, pode-se dizer que uma narrativa sempre revela um símbolo que permite apreender o sentido latente que se apresenta no conteúdo patente, correspondente ao seu sentido literal, e, ainda, possibilita que se apresente uma tradução da multivocidade semântica que fundamenta toda atitude simbólica, já que o símbolo é polissêmico (Cf. ARAÚJO, 1997).

Isso porque a imagem é entendida como elemento fundamental que orienta todo o nosso processo de simbolização e nossa consciência no que diz respeito à percepção do mundo, não se constituindo como um fenômeno da consciência ou uma faculdade independente. Assim compreendida, a imagem se apresenta como "a matriz do pensamento racionalizado", o "dinamismo organizador” da criatividade (DURAND, 2002), antecedendo o próprio conceito.

Nesse caso, a partir das imagens apresentadas por Sofia, foram revelados os sentidos atribuídos por ela à formação experienciada no âmbito do PIBID UFF-COLUNI, tendo como perspectiva uma análise hermenêutico-simbólica, que conjuga tanto o ato de explicar quanto o de compreender, assumindo este último um papel preponderante. O objetivo foi identificar as ideias-força presentes em seu discurso ${ }^{3}$, seja ele oral ou escrito, buscando entender quais representações simbólicas foram reveladas pelo seu imaginário a respeito da contribuição deste 
programa para sua formação e para o COLUNI. Ao assumir o estudo durandiano do imaginário como norteador e condutor, podemos entender que o imaginário atravessa todas as produções humanas e se epifaniza em cada manifestação criativa, tendo a imagem simbólica como elemento primordial no processo de seu desvelamento e de sua compreensão.

Para isso, foi necessário ouvir Sofia, partindo da premissa de que sua narrativa podia contemplar tanto os aspectos estritamente racionais de sua objetividade quanto manifestar os sentidos proporcionados pela sua vivência pibidiana, expondo suas representações e sua subjetividade. Araújo; Baptista (2003) ajudaram a entender um pouco mais sobre isso ao postularem que "[...] o semantismo do discurso não é redutível à sua estrutura formal, e que por isso mesmo é já sinal de uma presença simbólica, ainda que velada [...]” (p. 351). Dessa forma, a pesquisa narrativa se configurou como uma hermenêutica simbólica que permitiu que fossem desveladas as imagens e os simbolismos que Sofia produziu em relação a sua experiência pibidiana enquanto ela se narrou, se contou e estabeleceu uma íntima relação entre sua dimensão racional e imaginária. Isso pode ser percebido graças às contribuições de Chaves (1999), quando esta propõe a pesquisa narrativa como forma de "evocar imagens". Imagens estas que foram simbólicas e que disseram muito sobre "os modos de pensar, sentir e agir" de Sofia.

Neste sentido, a análise de sua produção (oral e escrita) pode revelar em torno de qual (ou quais) ideia(s)-imagem (redundância simbólica) se constelou seu discurso. Mais do que partir da palavra em si e do seu sentido denotativo ou da imagem pela imagem, o que se pretendeu foi desvelar o sentido conotativo e simbólico que essas imagens, em forma de palavras e de ideias, possuíram quando esta professora as utilizou para simbolizar sua atuação pibidiana e, assim, tentar compreender a analogia simbólica realizada por ela quando buscou fazer uma correspondência entre tais imagens e a sua própria vivência como bolsista do PIBID UFF-COLUNI.

Mas, antes disso, é necessário apresentar um pouco do PIBID e conhecer o seu "lado iluminado" e as suas normas tanto no âmbito da CAPES-MEC, quanto no contexto da UFF e do COLUNI. Vejamos o que o instituído tem a nos dizer. 


\section{PIBID CAPES-MEC E PIBID UFF-COLUNI - TRAÇOS DO INSTITUÍDO}

Ao falar do PIBID, coordenado pela Diretoria de Formação de Professores da Educação Básica da CAPES (anteriormente denominada de Diretoria de Educação Básica Presencial), órgão vinculado ao MEC, é importante salientar que tal programa, até fevereiro de 2018, se fundamentou legalmente em três documentos: na Portaria $n^{\circ}$. 096/2013, na Lei no. 12.796/2013, bem como no Decreto ${ }^{\circ} .7 .219 / 2010^{4}$. Podemos dizer que, em linhas gerais, de acordo com esses documentos, o PIBID busca "fomentar a iniciação à docência, contribuindo para o aperfeiçoamento da formação de docentes em nível superior e para a melhoria da qualidade da Educação Básica pública brasileira” (BRASIL, 2013a, p. 02), a partir dos objetivos estabelecidos.

Criado em 2007, quando foi divulgado o seu primeiro edital, o PIBID foi formalmente institucionalizado a partir do Decreto $\mathrm{n}^{\circ}$. 7.219, de 24 de junho de 2010, fato que garantiu a sua continuidade no contexto das políticas públicas educacionais como política de Estado, o que veio a atender a um desejo do MEC. Vale evidenciar que o PIBID surgiu num momento marcado por uma baixa procura pelos cursos de formação de professores, pelos altos índices de abandono do magistério e pela crescente demanda por professores de determinadas áreas do conhecimento, notadamente aquelas pertencentes ao campo das Ciências ditas exatas.

A princípio, o Edital MEC/CAPES/FNDE no 01/2007 teve como prioridade atender justamente as áreas com maior carência de professores: Física, Química, Biologia e Matemática. Todavia, “com os primeiros resultados positivos, as políticas de valorização do magistério e o crescimento da demanda, a partir de 2009, o programa passou atender a toda a Educação Básica, incluindo educação de jovens e adultos, indígena, a do campo e de quilombolas" (BRASIL, 2013b, p. 27). Com o Edital CAPES nº. 018/2010, o programa passou a permitir a atuação de instituições públicas municipais e comunitárias, confessionais e filantrópicas sem fins lucrativos, enquanto que o Edital Conjunto $n^{\circ}$. 002/2010 CAPES/Secad foi específico para atender as instituições que trabalhavam nos programas de formação de professores Prolind e Procampo. O Edital de 2011 não trouxe muitas modificações, mas foi caracterizado pelo aumento considerável na quantidade de bolsas oferecidas, chegando a mais de 26 mil. Isso também

4 Com a publicação da Portaria GAB nº. 45/2018, que revogou a Portaria nº. 096/2013, e do Edital $n^{\circ} .7 / 2018$ CAPES, o PIBID passou a ser regido por esses novos documentos e vem enfrentando várias modificações. No entanto, o presente artigo tomou como referência o período compreendido entre os anos de 2009 e 2018 (precisamente até fevereiro de 2018), o qual tinha como fundamento os 03 documentos citados no texto. Os dados apresentados também se referem a esse mesmo período. 
aconteceu com o Edital de 2012 que concedeu 49 mil bolsas. Em 2013, a CAPES lançou dois editais, oferecendo 72 mil bolsas: o de nº. 61, de 02 de agosto de 2013 e o de $\mathrm{n}^{\circ}$. 66, de 06 de setembro de 2013. O primeiro edital foi universal e teve o objetivo de convocar as instituições para apresentarem suas propostas. Esse edital foi marcado por uma peculiaridade: houve uma ampliação de sua abrangência e de seu alcance de maneira que as instituições públicas e privadas sem fins lucrativos e, ainda, alunos ProUni das instituições privadas puderam ser contemplados. Já o edital 66 foi lançado especificamente para contemplar os cursos de licenciatura intercultural, indígena e do campo, no que foi chamado de PIBID Diversidade. Nesse momento, ficou evidenciado, cada vez mais, a necessidade de fazer do PIBID uma política de Estado. Não foi à toa que o crescimento considerável desse programa no país acabou impulsionando a modificação do texto da LDB $n^{\circ}$. 9.694/96, através da Lei $n^{\circ} .12 .796$, de 04 de abril de 2013, que passou a estabelecer no $5^{\circ}$ parágrafo do seu artigo 62 :

$\int 5^{\circ}$ A União, o Distrito Federal, os Estados e os Municípios incentivarão a formação de profissionais do magistério para atuar na educação básica pública mediante programa institucional de bolsa de iniciação à docência a estudantes matriculados em cursos de licenciatura, de graduação plena, nas instituições de educação superior (BRASIL, 2013c).

No ano passado, a CAPES lançou, no mês de março, o Edital Capes nº. 7/2018 com o objetivo de convocar as instituições para apresentarem projetos de iniciação à docência. Podiam submeter projetos ao PIBID, naquele momento, as instituições públicas de ensino superior - federais, estaduais e municipais e também instituições comunitárias, confessionais e filantrópicas, bem como, privadas sem fins lucrativos que faziam parte de programas estratégicos do MEC como o REUNI, o ENADE, o Parfor e a UAB. A previsão para esse ano, de acordo com esse mesmo edital, era de um total de 45.000 cotas de bolsas na modalidade de iniciação à docência.

De 2007 até 2012, o PIBID concedeu um total de 52.409 bolsas em todo país, quantitativo que era de 3.088 bolsas em 2007. Dessas mais de 52 mil bolsas, 42.396 destinaram-se aos bolsistas de iniciação à docência (BID), 3.261 foram concedidas aos coordenadores e 6.752 , aos supervisores ${ }^{5}$. Se somarmos esses números aos 313 projetos selecionados pelos 02 editais de 2013, teremos um total de 90.254 bolsas concedidas, das quais 72.845 foram designadas à iniciação

5 Esses dados foram retirados do Relatório de Gestão 2009 - 2013 (BRASIL, 2013b), formulado pela Diretoria de Formação de Professores da Educação Básica (DEB/CAPES) e também de outros documentos disponíveis no site do PIBID: http://www.capes.gov.br/educacao-basica/capesPIBID. Tais informações contemplam dados referentes até o ano de 2013, o que inclui os editais até 2012. 
à docência, 11.717 à supervisão, 4.924 à coordenação de área, 313 à coordenação institucional e 455 à coordenação de gestão de processos educacionais (BRASIL, 2013b).

Para o ano de 2013, as perspectivas do PIBID previam, além de uma reorganização interna no âmbito da gestão do programa na CAPES, uma reestruturação do seu planejamento com vistas a sua expansão no país. Para isso, considerou-se importante o estabelecimento de uma reformulação das normas do PIBID, a qual se fundamentou em uma consulta pública aos seus membros (coordenadores institucionais, de área e de gestão, supervisores e bolsistas de iniciação). Como resultado desse trabalho de avaliação, foi lançada, em 18 de julho de 2013, a Portaria nº 096 que, a partir dessa data, passou a estabelecer o novo Regulamento do Programa Institucional de Bolsa de Iniciação à Docência, revogando, dessa forma, a Portaria nº. 260, de 30 de outubro de 2010. A Portaria $\mathrm{n}^{\circ} .096$ trouxe algumas alterações como, por exemplo, mudanças nos requisitos necessários para a concessão de bolsas de coordenação institucional e de coordenação de gestão de projetos educacionais; criação, por parte das IES, de uma Comissão de Acompanhamento do PIBID (CAP); reformulação da quantidade de coordenadores de área por subprojeto. Tais modificações representaram um avanço para a organização e a implementação do PIBID.

Todavia, os anos seguintes não foram nada fáceis para a manutenção desse programa em âmbito nacional. A partir de 2015, o PIBID veio sofrendo várias investidas que ameaçaram sua continuidade. Além dos vários cortes - a UFF sofreu com a redução de $20 \%$ no número de bolsas -, houve a tentativa por parte do Governo de revogar a Portaria 096/2013, mas a resistência das universidades e das escolas fez com que ocorresse um recuo por parte do MEC. Em 2017, quando todos estavam aguardando a publicação de um novo edital, o MEC divulgou na imprensa uma "modernização" do PIBID que acarretaria seu encerramento e lançaria a Residência Pedagógica como resultado dessa modernização. Houve muito embate, muita disputa com o objetivo de manter o PIBID e rejeitar a Residência Pedagógica que não era bem vista por conta do receio que se tinha de ela apresentar um perfil do Programa Mais Educação e, consequentemente, inserir o bolsista na escola com o propósito de cumprir tarefas.

No entanto, a Residência Pedagógica não seguiu os moldes do Mais Educação e se configurou como um projeto de estágio supervisionado que, na opinião de alguns, vem se fundamentando em um modelo de estágio ruim. O PIBID permaneceu e Residência Pedagógica também, de maneira que ambos os programas começaram a ser implementados simultaneamente nas IES e nas escolas, por um período de 18 meses (sem prorrogação), a partir de agosto do ano passado. 
Com o fim da vigência dos últimos Editais, nº. 61/2013 e nº. 66/2013, o MEC lançou a Portaria GAB no. 45, de 12 de março de 2018, que passou a ditar as normas para esse novo período do PIBID. Tal portaria trouxe muitas modificações, organicamente falando. Alterações que refletiram claramente a redução drástica de investimento na Educação.

Já no âmbito da UFF, o PIBID teve seu início no ano de 2010, atendendo ao Edital 02/2009/CAPES/DEB, através do projeto "PIBID UFF". Em 2011, dando continuidade ao programa e respondendo ao Edital 001/2011 CAPES/ DEB, a UFF apresentou o Projeto "PIBID UFF 2" com alguns ajustes e ampliações. De acordo com o próprio documento: “[...] o PIBID UFF 2 é concebido como uma expansão do PIBID na Universidade Federal Fluminense, em que novos projetos se integram aos já existentes para ampliá-los e para complementar a proposta em andamento." (UFF, 2011, p. 02).

Em 2012, atendendo ao Edital 011/2012 CAPES/DEB, que não efetuou chamada para novos projetos, foi possível realizar algumas reconfigurações naqueles já existentes. O PIBID passou por uma expressiva ampliação na UFF, de maneira a contar com 31 subprojetos em andamento. O número total de bolsistas aumentou consideravelmente, passando para 290, os quais foram alocados em 29 escolas públicas. Além disso, 18 docentes da UFF atuavam como colaboradores.

Para o ano de 2014, tendo em vista o atendimento ao Edital nº. 61/2013 CAPES/DEB, o Projeto PIBID UFF, apresentado a CAPES, passou a contar com um subprojeto Interdisciplinar, totalizando 25 subprojetos. A essa altura, o PIBID UFF já contava com 1136 bolsistas, além de 01 coordenador institucional e 04 coordenadores de gestão distribuídos em 70 escolas.

No que diz respeito aos aspectos teóricos, filosóficos e pedagógicos dos projetos "PIBID UFF, "PIBID UFF 2" e "PIBID 2013-UFF", podemos destacar a pesquisa e a reflexão sobre a prática como elementos essenciais para a formação inicial de professores, já que, assim, é possível, segundo tais documentos, encontrar soluções inovadoras para enfrentar as dificuldades presentes no dia a dia da prática docente. Em consonância com essa premissa, tais projetos assumiam como fundamentação teórica as contribuições de Donald Shön, no que dizem respeito à noção de Epistemologia da Prática; de Maurice Tardif, no que se referem à concepção de Saberes Docentes; e de Kenneth Zeichner, com relação à ideia de Reflexão Coletiva e Instituinte de Novas Práticas. Paralelamente a isso e evidenciando outro aspecto que foi basilar nos projetos, está a relação universidade - escola.

\footnotetext{
6 Partindo do fato de que o Edital 011/2012 CAPES/DEB não realizou chamadas para projetos novos e que o projeto UFF, relativo ao Edital 07/2018 CAPES, ainda estava em fase de seleção no momento de escrita da tese, a análise se baseou nos projetos referentes aos Editais 2009, 2011 e 2013, respectivamente: "PIBID UFF", "PIBID UFF 2"e PIBID 2013-UFF".
} 
A partir daí, de acordo com esses documentos, foi possível desenvolver uma formação inicial que permitia que o licenciando não só conhecesse a escola pública, mas também a compreendesse, de maneira a respeitar sua realidade e contribuir para a realização de aprendizagens significativas, baseando suas práticas educativas no exercício da criatividade, da pesquisa e do diálogo e tendo em vista uma prática profissional reflexiva. E, com isso, fazer com que a aprendizagem da docência in actu possibilitasse uma formação ancorada nos saberes da experiência, nos saberes das disciplinas e na reflexão. Fica clara também a constatação de que o PIBID UFF, além de ser um programa de formação inicial para os alunos das licenciaturas, também adquiria um caráter de formação continuada e de pesquisa para os coordenadores e para os supervisores envolvidos.

Dentro desse contexto, se insere o COLUNI-UFF, uma das instituições de Educação Básica em que o PIBID UFF foi implementado. Seu encontro com o PIBID se deu no ano de 2013, quando a UFF se organizava para atender ao Edital $\mathrm{n}^{\circ}$. 061. Tal subprojeto, em consonância com os projetos institucionais, também teve a pesquisa/reflexão sobre a própria prática do professor como base para a formação profissional deste. Isso era incentivado tanto pelas reuniões dos grupos de pesquisa, que congregavam os bolsistas de iniciação à docência, as supervisoras e as coordenadoras de área, quanto pela escrita de relatórios, "instrumentos de registro e reflexão do vivido que se constituíam numa importante ferramenta prático-teórica de produção de conhecimentos sobre a prática docente e os processos de aprendizagem e ensino" (UFF, 2013, p. 66). Outra questão que merece ser ressaltada se refere ao fato de se utilizar a concepção de Projetos de Trabalho, proposta por Hernández e Ventura, na sala de aula com os alunos. Além de aproximar professores de alunos, integrar várias áreas do conhecimento, exige que o professor desenvolva uma escuta sensível e atenta aos interesses dos discentes e também permite que se percebam outras possibilidades de se pensarfazer a docência a partir da busca de conhecimentos que tornem o processo de ensino e aprendizagem mais harmonioso e integrado. Sendo assim, o uso de tal metodologia se justificou por ser "uma forma de organização do currículo escolar que apresenta e desenvolve os conteúdos a partir de sua integração entre as áreas de conhecimento, tendo como princípios um tema central, a pesquisa e a participação de todos" (Ib, p. 64). Foi no âmbito do Subprojeto de Pedagogia (campus Niterói) que Sofia nos contou sobre sua participação no PIBID UFFCOLUNI. 


\section{SOFIA - A BUSCA PELA SABEDORIA}

O nome Sofia foi escolhido por significar pessoa sábia. Na Grécia Antiga, Palas-Atena era a deusa da sabedoria, da guerra, das artes e da justiça. Não é à toa que a busca pelo conhecimento e pelo aprender é marcante na vida dessa professora e recorrente em seu discurso.

Seu encontro com o COLUNI se deu quando ainda era discente do curso de Letras, em 2012. Com o tempo, Sofia conseguiu uma bolsa de extensão e passou a atuar como professora auxiliar na turma do $5^{\circ}$ ano. Mais tarde, já formada, foi contratada como professora e assim permaneceu de 2013 a 2016. Por ter atuado no COLUNI a partir de diferentes vínculos, Sofia pode enxergar essa escola de lugares distintos. Nesse espaço, ela passou pelas salas de algumas turmas do $1^{\circ}$ e do $2^{\circ}$ segmentos do Ensino Fundamental e pode vivenciar o sentido que o magistério tem para ela: fazer mediação, facilitar o processo de ensino e aprendizagem do aluno. O COLUNI foi o lugar em que se deu sua iniciação à docência, espaço dos começos, lugar inaugural e o PIBID, também, esteve presente nesse processo iniciático que caracterizou sua transformação de aprendiz de mestre em mestreaprendiz.

Sua atuação no PIBID se deu ao longo do período em que trabalhou no COLUNI, ou seja, assim que entrou no colégio, iniciou sua participação também no programa, e, ao que seu discurso indica, essa aproximação ocorreu de maneira bem intencional. Isto é, ela possuía uma ideia do trabalho que era efetivado no PIBID e se sentiu atraída pela

[...] proposta de realmente colocar em prática modos de dialogar, pesquisar e aprimorar o processo de conhecimento em parceria com os alunos e profissionais de outras áreas de conhecimento, pois tínhamos a vantagem de ter subsídios do governo (recursos financeiro e bumano) para realizar as pesquisas e atuar com materiais e ferramentas diversificadas (Grifos meus).

Diálogo, pesquisa e integração foram ideias-imagem que marcaram o discurso de Sofia. A possibilidade de colocar em prática uma educação complexa, que, segundo ela, seria uma alternativa à fragmentação e à desarticulação dos conbecimentos a partir de uma integração e de um entrelaçamento das diversas áreas do saber, foi algo que a marcou em sua experiência com o PIBID. Isso ficou mais claro, quando ela apontou como ponto positivo do PIBID a sua razão dialógica e, principalmente, quando ela apresentou a imagem-palavra complexidade para simbolizar o que o PIBID representou para ela. Complexidade que ela associou a 02 (duas) questões que foram fortes nessa sua experiência pibidiana e a atingiram diretamente: ressignificação do meu próprio lugar como pessoa e cidadã e a importância da não 
fragmentação dos saberes e dos conbecimentos. À primeira questão, Sofia associou o fato de não ter vivenciado, ao longo de sua vida de escola/faculdade, uma formação que incentivasse a curiosidade, a pesquisa, a problematização. Já à segunda, foi relacionada a oportunidade que ela teve de efetivar um trabalho fundamentado numa desfragmentação dos conhecimentos e do ensino, numa REligação de saberes e de pessoas que contribuiu para que ela vivenciasse um processo de (auto/trans)formação.

Arriscamos a dizer que Sofia experimentou o que Morin (2003b) nos fala sobre a necessidade de se "pensar a reforma" e de se "reformar o pensamento" ao refletir sobre o pensamento complexo e sobre a fragmentação dos conhecimentos. Para ele, pensar de maneira complexa exige uma reforma do pensamento por meio do ensino transdisciplinar, capaz de formar cidadãos planetários, solidários e éticos, aptos a enfrentar os desafios dos tempos atuais. E isso vai ao encontro do que Sofia pensa com relação a sua atuação no PIBID. Ao falar sobre algo que foi um ponto alto nessa sua experiência pibidiana, ela destacou a influência de tal programa em fazer com que se rebelar contra a fragmentação e a desarticulação dos conbecimentos em busca de uma proposta transdisciplinar passasse a ser um desafio pessoal.

REligar, REintegrar, REuniros saberes das diversas áreas de conhecimentos, fazer seus sujeitos dialogarem se constituíram em uma bússola que passou a guiar os seus "modos de pensar, sentir e agir" a docência. Sua maneira de ver e compreender o mundo passou a contemplar um pensamento que busca distinguir e unir os conhecimentos, pois ela percebeu que aquela maneira de pensar, baseada em um pensamento que tende a isolar e a separar as coisas não dá conta da multidimensionalidade e da complexidade da vida. E foi esse movimento de incorporação dessa outra forma de ver a vida, a qual se fundamentou em uma razão aberta, numa perspectiva dialógica e multidimensional e que exige a renúncia de uma postura que julga a realidade segundo pré-conceitos reducionistas, que permitiu com que ela ampliasse o seu olhar e a sua escuta diante do que se passava.

Baseada nisso, Sofia trouxe um trecho de autoria de Tierno Bokar (18751939) ${ }^{7}$ que se encontra no livro "O sábio de Bandiagara"8 de Amadou Hampaté Bâ (1901-1991) $)^{9}$ para representar sua experiência pibidiana:

$7 \quad$ Místico maliano do início do século XX conhecido pela sua mensagem de tolerância religiosa e amor universal. Disponível em: https://en.wikipedia.org/wiki/Tierno_Bokar

$8 \quad$ Escrito em 1957 e reescrito em 1980.

9 Escritor malinês, mestre da tradição oral africana. 
Se queres saber quem sou,

Se queres que te ensine o que sei,

Deixa um pouco de ser o que tu és,

E esquece o que sabes.

O contato com esse livro ocorreu devido aos muitos encontros estabelecidos pelo movimento impulsionador de busca proporcionado pelo PIBID. Foi a partir desse movimento, que Sofia pode ter acesso a novos conhecimentos, aprimorados pela pesquisa, e se aproximar de sujeitos de outras áreas do saber na tentativa de buscar preparação para esse novo modo que estava funcionando com os alunos de desafiá-los a pesquisar ${ }^{10}$.

O trecho escolhido faz parte de um dos muitos livros escritos por Amadou Hampaté Bâ, considerado mestre da tradição oral africana. Em "O sábio de Bandiagara", ele conta histórias vivenciadas desde a sua infância até sua juventude, tomando como base a lembrança de fatos significativos que marcaram sua trajetória, principalmente aqueles relacionados aos ensinamentos de seu mestre Tierno Bokar. Sofia trouxe um exemplo dos muitos ensinamentos deixados por esse sábio aos jovens de sua tribo, que foram, pacientemente, transmitidos de boca a ouvido, de mestre a discípulo, ao longo dos séculos. Sua escolha não foi por acaso. A tradição oral africana tem como base a experiência e a iniciação. Ela conduz o homem à sua totalidade e, em virtude disso, pode-se dizer que contribui para criar um tipo de homem particular. Ela não só permite uma visão peculiar do mundo, mas também possibilita uma presença específica nele porque parte do entendimento de um mundo que é concebido como um todo em que todas as coisas se religam e interagem. Por isso, Sofia se sentiu afetada por essa imagemtexto. Ela veio ao seu encontro, revelando o que ela experimentou com o PIBID e o sentido deste para ela.

A exemplo do que o trecho nos sugere, Sofia precisou se colocar numa posição de aprendiz, tentando se despir de todo pré-conceito que possuía a respeito da docência, do ensinar, do aprender. Abrir mão de alguns conhecimentos, saberes e atitudes incorporados e inscritos nela, a fim de ampliar seu olhar, a sua maneira de ver o mundo. Foi preciso renunciar ao hábito de julgar tudo segundo uma visão unidimensional, fragmentada e se permitir abrir mão das suas certezas e desenvolver uma "escuta sensível" perante os conselhos, os ensinamentos, as palavras dos vários mestres que cruzaram seu caminho: foi preciso REinventar-se, (auto/trans)formar-se. Ela se sentiu encantada pela possibilidade de efetuar uma prática docente fundamentada no pensamento complexo, principalmente no que

10 Sofia se refere à proposta de Projeto de Trabalhos de Hernández e Ventura adotada pela equipe do PIBID do COLUNI. 
tange à REligação de saberes em que ela se fundamenta. Sofia experienciou o que Juan de Mairena, citado por Morin (2003b), nos propõe como papel da escola que é "repensar o pensamento e 'des-saber' o sabido" (p. 21), se preocupando em estimular essa mesma atitude nos seus alunos:

Esse trecho nos leva a pensar como devemos esquecer um pouco o que sabemos pra saber um pouco do outro, porque, senão, não temos como saber nada. Tem a ver com essa busca durante o momento que eu estava no curso com ela ${ }^{11}$, mas também ressignificando para as crianças lá na sala de aula, tentando passar um pouco dessa mensagem pra elas.

Isso ficou nítido quando ela começou a contar sobre o desenrolar do Projeto África, um dos muitos projetos desenvolvidos no âmbito do PIBID, e, especialmente, sobre o movimento de busca e de pesquisa empreendido por ela ao longo da implementação de tal projeto: Foi um desafio: eu primeiro tive de fazer um resgate daquilo que me foi colocado, que estava pré-estabelecido para depois repensar e ressignificar isso. Um processo de formação/pesquisa mesmo. E, a partir daí, começar a buscar e trocar com o outro. E esse outro foi essencial nessa jornada.

Foi uma descoberta, porque trabalhamos com vários projetos ao longo do ano: teve insetos, teve moda, teve a África. Não sei se você sabe qual é a metodologia ${ }^{12}$ : tem o indice, que é, basicamente, um apanhado sobre o que sabemos a respeito do tema, nesse caso, a África; num segundo momento, conversamos sobre o que gostaríamos de saber e, em seguida, onde nós podemos pesquisar isso. Eu fui atrás de alguns especialistas professores, por exemplo, a professora de Ciências me ajudou muito.

Teve um estudante que eu conheci aqui na faculdade [de Educação]. Ele foi ao COLUNI, falou a partir do ponto de vista dele. Foi bem interessante. Teve um professor que trabalhava há muitos anos em outra faculdade e que também foi ao COLUNI conversar com as crianças. Ele trouxe o olhar dele, as coisas que ele ouvia nas histórias, o que ele tinha de memória, trouxe fotos. Então teve toda uma troca diferenciada.

Todos eles a auxiliaram e com eles foi possível estabelecer um diálogo, uma aproximação dos conhecimentos, dos sujeitos, dos espaços. Esses encontros permitiram interações, retroações, inter-retroações, REligação de saberes não só por parte de Sofia, mas também nesses outros sujeitos citados: ela [professora Ciências COLUNI] também foi provocada de alguma maneira, ela também teve essa busca e fez. um trabalho muito legal. Diálogo que foi fundamental para que esse REconectar acontecesse e que possibilitou que a África se tornasse viva no espaço da sala de aula do COLUNI e pudesse ser conhecida a partir de um olhar complexo que permitiu aos alunos pensá-la de maneira mais abrangente e completa, porque tal olhar se fundamentou na integração 
Seguindo esse mesmo movimento, Sofia falou sobre as contribuições do PIBID para o COLUNI, ou melhor, da experiência pibidiana deste. E para simbolizá-la, ela escolheu um trecho de "O livro dos abraços" de Eduardo Galeano:

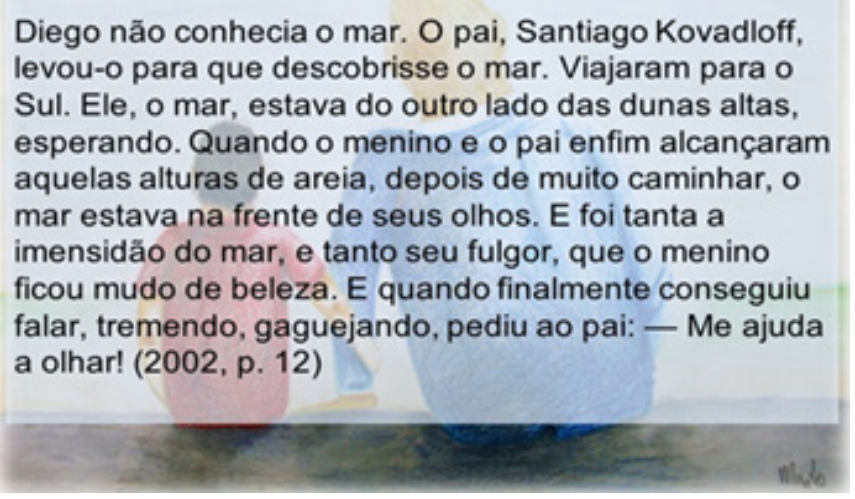

Imagem de fundo disponível emhttp://ludmilasaharovsky.com/2012/11/o-livro-dos-abracos.html

O trecho trouxe a imagem do mar que, normalmente, está associada à ideia de vida, contemplando também seu par complementar, antagônico e concorrente: a morte. Ou seja, o mar é, ao mesmo tempo, lugar de nascimentos, de transformações, de Renascimentos e de morte (CHEVALIER e GHEERBRANT, 2009, p. 592-593). Para Sofia, o que mais chamou sua atenção nesse trecho foi a ideia de imensidão que está associada à imagem do mar e, principalmente, a sensação de pequenez que ele provoca em nós, diante da impossibilidade de darmos conta dessa imensidão sozinhos. Mais uma vez, ela destacou a importância de alguém para nos ajudar com isso. E esse alguém pode ser qualquer um, segundo ela, apesar de ter sido representado pelo pai no trecho que ela trouxe. Suas palavras explicam melhor:

Talvez o pai possa representar o professor, mas eu acho também que o aluno, às vezes, assume esse papel de pai. O professor é pai, os outros especialistas são pais, a coordenadora... eu sou muito agradecida a ela, foi um pai também, nesse sentido de "me ajudar a olhar", a olhar esse mar... fico até emocionada. Esse mar que é essa complexidade, o ser bumano. Não é só olhar o conhecimento não, mas o outro [...]. Eu precisei de outros para me ajudar: o aluno africano me ajudou, o professor de Cabo Verde me ajudou, a coordenadora me ajudou e, às vezues, em 
alguns momentos, ela me confundiu e eu tive de ir lá na [citou o nome da professora do curso de extensão ministrado na UFF]: me ajuda a olhar? Ai ela também falava: "olha Sofia, eu não posso falar a partir do ponto de vista de uma pessoa negra, porque eu não sou, mas eu sou uma pessoa que acredita nisso e nisso. Desse lugar aqui que eu vou te falar". Ai você, caramba, é desse lugar que eu tenho que falar. Eu não posso também colocar esse peso em cima de mim desde que as pessoas saibam que é desse lugar que eu estou falando. Eu acho que está até fechado um ponco esse texto, porque parece que o pai ou é Sofia ou quem está ali na frente das crianças, mas esse pai é dinâmico no processo.

Dessa forma, a imagem do pai está relacionada a alguém que nos auxilia a olhar o mar e sua imensidão, que nos orienta na caminhada, que nos conduz no processo de conhecimento e de (auto/trans)formação que é complexo.

\section{CONSIDERAÇÕES FINAIS}

É interessante notar que, apesar de ter apresentado essa imagemtexto como símbolo da experiência pibidiana do COLUNI, Sofia acabou, ao explicar o porquê dessa escolha, enfatizando sua própria experiência pibidiana. $\mathrm{O}$ que nos permite crer que ambas as experiências se confundiram (co-fundir), se amalgamaram. Atrevemo-nos a dizer que, assim como para ela, o PIBID possibilitou que o COLUNI experimentasse um ensino mais abrangente por se pautar numa REligação dos conhecimentos, no diálogo entre as suas várias áreas e seus sujeitos. Um ensino fundamentado no entendimento de que integrar é inerente a nossa natureza e, qualquer pensamento que vá à contramão disso, reduz nosso campo de visão, estreitando, simplificando e atrofiando o nosso olhar, porque desconsidera que diante do mar da vida, para que possamos enxergá-lo na sua complexidade e captar todas as suas dimensões, segundo uma relação antagonista, concorrente e complementar, é necessário que todas as áreas do conhecimento e não somente o conbecimento dito científico nos ajudem a olhar.

Assim, pode-se afirmar, também, que o processo de (auto/trans) formação experienciado por Sofia no âmbito do PIBID UFF-COLUNI - vivido também pelas outras professoras que fizeram parte da pesquisa -, contemplou, numa dinâmica dialógica, momentos de REorganização que contribuíram para que ocorresse uma "reforma do pensamento", como nos fala Morin (2003b), a qual impulsionou uma REssignificação dos "modos de pensar, sentir e agir" a docência, a educação e a formação dessas professoras, bem como, uma REestruturação cognitiva que permitiu que elas empreendessem outras práticas pedagógicas, outros comportamentos e outras atitudes; enfim, forjassem um outro estilo pessoal de ser professora. 


\section{REFERÊNCIAS}

ARAÚJO, Alberto Filipe; SILVA, Armando Malheiros. Mitanálise e interdisciplinaridade: subsídios para uma hermenêutica em educação e ciências sociais. Braga: Universidade do Minho, 1997.

; BAPTISTA, Fernando Paulo (coords.). Variações sobre o imaginário: domínios, teorizações e práticas hermenêuticas. Lisboa: Instituto Piaget, 2003. (Coleção Pensamento e Filosofia).

BRASIL. Coordenação de Aperfeiçoamento de Pessoal de Nível Superior. Portaria $\mathbf{n}^{\mathbf{0}} \mathbf{0 9 6}$, de 18 de julho de 2013. Aprova as novas normas do Programa Institucional de Bolsa de Iniciação à Docência - Pibid. Brasília, 2013a. Disponível em: http://www.capes.gov.br/images/stories/download/legislacao/ Portaria260_PIBID2011_NomasGerais.pdf. Acesso em: 25 set. 2019.

BRASIL. Coordenação de Aperfeiçoamento de Pessoal de Nível Superior. Relatório de Gestão Pibid 2009-2013 da Diretoria de Formação de Professores da Educação Básica. Brasília, 2013b. Disponível em: http://www. capes.gov.br/images/stories/download/bolsas/1892014-relatorio-PIBID.pdf. Acesso em: 25 set. 2019.

BRASIL. Presidência da República. Lei no $\mathbf{0}$ 12.796, de 04 de abril de 2013. Altera a Lei no 9.394, de 20 de dezembro de 1996, que estabelece as diretrizes e bases da educação nacional, para dispor sobre a formação dos profissionais da educação e dar outras providências. Brasília, 2013c. Disponível em:http://www.planalto.gov. br/ccivil_03/_Ato2011-2014/2013/Lei/L12796.htm. Acesso em: 25 set. 2019.

BRASIL. Coordenação de Aperfeiçoamento de Pessoal de Nível Superior. Portaria GAB $\mathbf{n}^{\mathbf{0}}$. 45, de 12 de março de 2018. Dispõe sobre a concessão de bolsas e o regime de colaboração no Programa de Residência Pedagógica e no Programa Institucional de Bolsa de Iniciação à Docência (Pibid), Brasília, 2018. Disponível em https://www1.capes.gov.br/images/stories/download/ legislacao/16032018_Portaria_45_Regulamento_PIBID_e_Residencia_ Pedagogica_SITE.pdf. Acesso em 30 set. 2019. 
CHAVES, Iduina Edite Mont'Alverne Braun. A pesquisa narrativa: uma forma de evocar imagens da vida de professores. In: SANCHEZ TEIXEIRA, Maria Cecília Sanchez; PORTO Maria do Rosário Silveira (Orgs.). Imagens da Cultura: um outro olhar. São Paulo: Plêiade, 1999, p.121-138.

- Vestida de azul e branco como manda a tradição: cultura e ritualização na escola. Niterói: Intertexto; Rio de Janeiro: Quartet, 2000.

Prefácio. In: ARAÚJO, Alberto Filipe e SANCHEZ TEIXEIRA, Maria Cecília. Gilbert Durand: imaginário e educação, Niterói: Intertexto, 2011.

CHEVALIER, Jean; GHEERBRANT, Alain. Dicionário de símbolos: mitos, sonhos, costumes, gestos, formas, figuras, cores, números. 24 ed. Rio de Janeiro: José Olympio, 2009.

DURAND, Gilbert. As estruturas antropológicas do imaginário: introdução à arquetipologia geral. $3^{\text {a }}$ ed. São Paulo: Martins Fontes, 2002.

MAFFESOLI, Michel. A lógica da dominação. Rio de Janeiro, Zahar, 1979.

A Contemplação do Mundo. Porto Alegre: Artes e Ofícios Ed, 1995.

O Conhecimento comum: introdução à sociologia compreensiva. Porto Alegre: Sulina, 2010.

MORIN, Edgar. O problema epistemológico da complexidade. Lisboa: Publicações Europa-América, 1983.

. A cabeça bem-feita - repensar a reforma, reformar o pensamento.

Rio de Janeiro: Bertrand Brasil, 2003.

Ciência com consciência. Ed. Revista e modificada pelo autor. 13 ed. Rio de Janeiro: Bertrand Brasil, 2010.

Terra-Pátria. 6 ed. Porto Alegre: Sulina, 2011a. 
O método VI: Ética. 4 ed. Porto Alegre/RS: Sulina, 2011b.

UNIVERSIDADE FEDERAL FLUMINENSE. Pró-Reitoria de Graduação. Programa Institucional de Bolsa de Iniciação à Docência (Pibid)/ Detalhamento do Projeto Institucional. Niterói/RJ, 2011.

. Pró-Reitoria de Graduação. Proposta Edital no 61/2013 - PIBID

2013-UFF. Niterói/RJ, 2013.

ROBERTA LOPES ALFRADIQUE HARDOIM é Doutoranda no Programa de PósGraduação em Educação da Universidade Federal Fluminense (UFF), Mestre em Educação pela mesma instituição (2013), integrante do Núcleo de Estudos e de Pesquisas Cultura, Imaginário, Memória, Narrativa e Educação (CIMNE - UFF) e graduada em Pedagogia também pela UFF (2004). Atualmente é Técnica em Assuntos Educacionais no Instituto de Filosofia e Ciências Sociais (IFCS) da Universidade Federal do Rio de Janeiro (UFRJ), atuando na Secretaria Acadêmica da Diretoria Adjunta de Graduação (DAG/IFCS).

E-mail: rlalfradique@gmail.com

IDUINA MONT'ALVERNE BRAUN CHAVES Possui graduação em Pedagogia pela Universidade Estadual do Ceará (1975) e doutorado em Educação pela Universidade de São Paulo(1998). Atualmente é professor adjunto da Universidade Federal Fluminense.

E-mail: iduina@globo.com

Recebido em setembro de 2019

Aprovado em outubro de 2019 